\title{
Calcification of the soft tissue of the hands following collagen injection: a case report
}

\begin{abstract}
Calcification (deposits of calcium phosphate) or calcinosis may occur in many different soft tissues including the soft tissues of the hands. It occurs in a vareity of local and systemic conditions. Calcification can be the body protective response to injury, as well as a part of natural inflammatory reaction to infection, trauma, tumour, or autoimmune disorders. In our case calcification of the soft tissues of both hands occurred 2 years after injection of collagen into the webspaces of the hands. The primary symptom was only a morning stiffness without swelling of the small joints or any other large joints. The onset was insidousIy and was not assocaited with pain. All laboratory parametrs did not show any inflammation or an assocaition of an autoimmune diseases. The calcification appeared in both hands as a late infammatory reaction to the injection of collagen which may mimic those seen in patients with scleroderma or dematomyositis. The treatment of such cases should be sympomatic with NSAIDS and patient assurance. Calcification as a result of callagen injection should be considered in the differentail daignosis in autoimmune diseases which assocaited with calcification of the soft tissues
\end{abstract}

Volume 5 Issue I - 2016

\section{Khalaf Moussa}

Dubai bone and joint center, United Arab Emirates

Correspondence: Khalaf Moussa, Senior consultant orthopedic surgery, Dubai bone and joint center, Al Razi Building, Ist Floor, PO Box-I I8855, Dubai, United Arab Emirates, Tel 972000000000 ,Email kmoussa@gmx.de

Received: March 14, 2016| Published: May 24, 2016

\section{Case description}

51 years old female, weight $103 \mathrm{~kg}$ and height $1.55 \mathrm{mt}$, presnted to our clinic complaining of pain and stiffness of both knees and small joints of the hands. The morning stiffness period was 5-10 minutes. There was no history of swelling. She was complaining also of neck pain, no headache, no dizziness, no blurring of vision or radiation of pain. There was no history of fever, difficulty of swallowing, No history of weight loss or change apitite. No bladder or rectal ditubances. No history of skin rashes or sun sensitivity. No Raynauds phenomenon or digital skin ulcers. No allergy. No family history of rheumatic diseases. Arthrocopy of the right knee was carried out 7 months ago. Due to the feeling that the web spaces on the dorsum of the hand were empty, a cosmotic operation was done and a collagen was injected into the $2^{\text {nd }}-4^{\text {th }}$ web spaces of both hands 2 years ago. Examination of both hand s revealed tenderness over the proximal- and the distal- interphalangeal joints. No swelling. Free range of motion. Fist was full. No neurological or vascular signs. Skin was intact and of normal elasticity. Both shoulders were free. Clinical examination of both knees revealed tenderness over the medial joint line but no meniscus sign, retropateller friction pain. No effusion. The range of motion of both knees was free. Examination of the cervical spines showed spasm of the paraspinal muscles.tenderness over the spinous process of the lower cervical spines. Dorsiflexion and right rotation were painful but no radiation. All laboratorory investigations inculding ANAs, Anti-lupus antibodies, RF, CCP, cardiolipin IGG, IGM, $\mathrm{T} 3, \mathrm{~T} 4$, calcium, phosphorus uric acid and 25-hydroxivitamin D were whithin normal range. Only chlolesterol was elevated $250 \mathrm{mg} / \mathrm{dl}$ (normal range 200-240).

The radiological studies of the cervical spines showed degenerative changes of the facet joints and spondylotic changes of $\mathrm{C} 4 \mathrm{C} 5$, C5C6. No erosion or calcification. Varus ostearhritic changes of both knees.

The radiological studies of both hands (Figure 1) revealed clumps of calcification of the soft tissues suggesting a connective tissue disoerder. The calcification extended to involve the subcutanous tissue which can be seen on the lteral view. A periosteal reaction as a part of the infammatory process also can be seen at the medial border of the $5^{\text {th }}$ metacarpal bone. Xray of both feet did not reflect any bony changes. Only a mild hallux valgus deformity.

\section{Discussion}

A Calcification can be classified into metastatic calcification and dystophic calcification. Metastatic calcification occurs in hypercalcemic states and are found in kidney, lung, brain, eyes, skin, subcutaneous and periarticular tissues and arterial wall. Such types of calcinosis is usually relted to other underlying conditions, such as hyperparathyrodism, hypoparathyrodism or renal diseases. ${ }^{1-3}$ Tumoral calcinosis is included in this category, however, it is separated from other forms of metastatic calcification because there are no internal organs involved. This condition is charactarized by the rapid development of a large, multi-lobulated, calcific masses in the subcutaneous tissue and muscles surrounding the hips, shoulders, elbows, hands, and chest walls. Dystophic cacification seen in patients who have calcium deposits in the soft tissues but have no generalized distubances in calcium or phosphorus mtabolism. It often seen at sites of previos inflammation or damage to the skin. Calcinosis has been associated with connective tissue disease, such as in systemic sclorosis (scleroderma) or polymyositis-dermatomyositis. ${ }^{4}$ Usually this group of patients have other symptoms that can guide to the daignosis and confirmed by the abnormal laboratorory results.Our case did not have any symptoms other than the history of morning stiffness which last for 5-10 minutes and her laboratory investigations did not show any positive results.

Calcification often produces no symptoms, instead, calcification is most frequently dicovered on X-ray. Calcium phosphate crystals have a remarkable tendency to aggregate into snowball-like clumps and are invariably associated with paticular collagens. Collagens are fibrous, insoluble protiens found in the connective tissues including bones, skin, cartilage and ligaments. This has been shown in our case where the calcium phosphate react with injectable collagen and appeared as an aggregates and clumps of calcification around the soft tissues of both hands. Despite the fact that the small joints of the hands were not affected, the morning stiffness of both hand may be attributed to this iatrogenic calcification of collagen. The treatment of such case should 
be symptomatic using nonsteriodal anti-inflammatory drugs and patient reassurance.
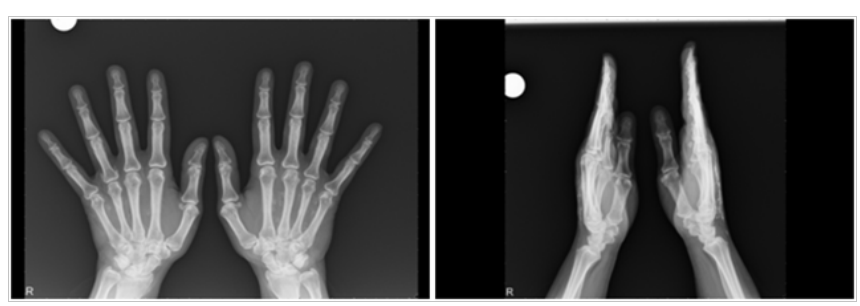

Figure I X-ray of both hands of 5 I years old woman showing calcification of the soft tissues 5 years after injection of collagen into the web spaces.

\section{Conclusion}

The use of collagen injection for cosmotic purposes could cause iatrogenic calcification of the soft tissues mimic those seen in auto-immune diseases like scleroderma or dermatomyositis and systemic lupus erythromatosis. ${ }^{5-6}$ The history of cosmotic surgeries using collagen which became very common specailly in females should be assessed The appearanc of calcification at the site of collagen injection as a late sequale of inflammatory reaction should be taken into consideration as a differentail diagnosis in cases of calcification that can be seen on X-ray.

\section{Acknowledgments}

None.

\section{Conflicts of interest}

None.

\section{References}

1. Brown EM. The pathophysiology of primary hyperparathyrodism. $J$ Bone Miner Res. 2002;17(suppl 2):N24-N29.

2. de Francisco AL. Secondry hyperparathyrodism review of the diseases and its treatment. Clin Therap. 2004;26(12):1976-1993.

3. Bilezikian JP. Management of acute hypercalcemia. $N$ Engl $J$ Med. 1992;326(18):1196-2003.

4. The J, Whiteley G. MRI of soft tissue masses of the hand and wrist. $B r J$ Radiol. 2007;80(949):47-63.

5. Sonthheimer RD. Dermatomyositis an overview of recent progress with emphasis on dematologic aspects. Dermatol Clin. 2002;20(3):387-408.

6. Sven J. A Systemic lupus eryrthromatosis with ectopic calcification. Brit J Dermatol. 1971;84(2):191-192. 